\title{
Communicating and learning maritime safety culture-development and evaluation of a didactic design based on an interactive module
}

\author{
Mikael Blomé • Åsa Ek
}

Received: 25 January 2013 / Accepted: 17 September 2013 / Published online: 1 October 2013 (C) The Author(s) 2013. This article is published with open access at Springerlink.com

\begin{abstract}
To be able to disseminate knowledge about maritime safety culture and safety management to different actors in the Swedish maritime sector, a didactic design was developed and evaluated. The didactic design includes an interactive scenario-based module and a teacher's guide and is based on a model for experience-based learning that connects theory and practice by a cyclic approach. Students at upper-secondary maritime schools were chosen as a user group and the didactic design was adapted for them. The didactic design was tested in a classroom setting including interaction with the students and a followup 1 week later. The didactic design was successful in immediately creating a relevant discussion about safety culture, and the student group could, on the whole, remember and describe all scenarios a week after the presentation of the material. The results were overall positive regarding usability and user experience with a potential for further development and implementations. The participating teacher at the school was also very positive and felt he would be able to apply the didactic design with support of the teacher's guide.
\end{abstract}

Keywords Maritime safety Educational technology · Participative design · Interactive module $\cdot$ Knowledge visualization $\cdot$ Communication support

\section{Introduction}

\subsection{Safety knowledge}

A Swedish maritime safety project was carried out to yield new knowledge for increased safety at sea. Part of the project focused on human and organizational factors, safety management, and safety culture on board ships (Ek and Akselsson 2005; Mejia et al. 2007). Safety culture is a vital factor for maintaining and improving safety on board ships, and concerns having an awareness of risks and the knowledge, ability,

M. Blomé $(\bowtie) \cdot \AA$ A. Ek

Ergonomics and Aerosol Technology, Department of Design Sciences, Faculty of Engineering, Lund University, P.O. Box 118, 22100 Lund, Sweden

e-mail: mikael.blome@design.lth.se 
and willingness to prevent them. At the end of the maritime safety project, discussions were held with representatives from the maritime sector, including shipping companies, vessel crews, the Maritime Department at the Swedish Transport Agency and trade unions. They all emphasized the need for disseminating to the sector the results and knowledge gained in the project. The dissemination of safety knowledge must reach actors at all levels in the sector for increased safety awareness. Positive attitudes to safety and a good safety culture across the sector are a foundation for good safety at sea; understanding of these issues needs to take root early in a seaman's education. The aim of this paper is to present the development and evaluation of a didactic design that through visualization of knowledge and animations educate students at upper-secondary maritime schools in the area of safety culture on board ships and continuous safety improvement.

An individual's safety attitudes and behaviours are generally instilled early in life. A promising way to create insight and awareness about maritime safety issues early in a seaman's career is through the safety education offered in maritime secondary schools. This can be an efficient way to establish and maintain a maritime safety culture on an individual level, but also to develop and shape a good safety culture in the Swedish maritime sector on a long-term basis.

\subsection{Safety knowledge educational material}

In general, the dissemination of research results to the industry is not that straight forward. The research-practice gap is receiving increasing attention (Bruneel et al. 2010; Chung and Shorrock 2011). The gap is frequently due to the failure to present research findings in appropriate and accessible forms for different audiences (Dowie 1996; Moffatt et al. 2000). Knowledge dissemination can be defined as tailoring the research findings and messages to a particular target audience (Lomas 1993; Gagnon 2011). Knowledge dissemination is related to the term 'knowledge transfer', which is the process of getting stakeholders to use the knowledge (Graham et al. 2006).

In the current research study, the challenge was thus to develop appropriate educational material to enhance the student learning process and that would also take into account today's technology to support the learning situation. During the development process, questions arose on how safety culture and safety management should be described so that it was appropriate for young students. Could principles of interactive technology be used to visualize safety culture knowledge with pictures and illustrative on-board scenario animations? Could the technology support the interaction between teacher and students?

It is clear that well-selected or well-constructed pictures reliably improve the reading-to-learn process (Levie and Lentz 1982; Mayer 1989; Carney and Levin 2002). The ability to design informative pictures and interactive illustrations has increased with advanced information and communication technology. It is relatively easy to replace static pictures with animations in information systems, but several studies have shown a lack of the general superiority of animations when compared with static pictures on learning outcome (Tversky et al. 2002; Lewalter 2003). However, a meta-analysis of instructional animations versus static pictures carried out by Höffler and Leutner (2007) found a rather substantial overall advantage of the former over the latter, and this advantage was particularly evident under specific 
combinations of instructionally relevant circumstances. Examples of these circumstances are guidelines and product instructions in industrial organizations where the use of pictures and animations has proven to work out very well to visualize information (Blomé et al. 2006; Blomé et al. 2003). However, 'safety culture' deals with, for example, the handling of and attitudes to equipment, and not the actual product. Students may also lack experience on which to build their knowledge. This stresses the importance of applying a suitable didactic approach where new technology supports the learning situation.

Laurillard (2002) describes principal media forms with the learning experiences they support and the methods used to deliver them. Considering the current study, the learning experiences should be investigating and exploring, which according to Laurillard (2002) are supported by an interactive media form delivered through CD and web resources technology. The learning experiences should also involve students in discussions that have a communicative media form delivered by seminar methods. The technological advancement have resulted in virtual worlds and social networking services that could replace classroom teaching; however, learners and teachers may lack the necessary digital literacy skills needed and time to explore how these technologies can be used (Brooks et al. 2012).

A typical interactive media form is web-based material suitable for distance courses where students gain control of the learning by freely pursuing links and searching for information based on individual learning strategies and curiosity. Classroom teaching offers good opportunities to apply different seminar methods to communicate and interact with a group of students. In the UK, promising attempts have been made in the maritime educational system, specifically in the area of integrated coastal management, to enhance student learning processes by the application of experiential learning theories on web-based distance learning and classroom courses (Fletcher 2001; Fletcher and Dodds 2003).

It would be valuable to combine the technological benefits from interactive media to support the interaction in classroom seminars. Muirhead (2004) argues that new technology must be viewed as a complementary methodology to traditional means, not a replacement, with the challenge to determine where technology can enhance or improve the learning situation in an interesting and cost effective manner. Today's teachers are under great pressure to engage students in the learning process through the use of computing resources. Muirhead (2004), though, describes this as a daunting prospect since maritime education and training (MET) institutions generally have failed to provide teachers with the training necessary to use new technology. Muirhead concludes that the key is better awareness of the potential of technology in education and increased teacher training.

\subsection{Aim of paper}

This paper presents the results of a study that developed and evaluated a didactic design including an interactive module with suitable visualizations to educate students at upper-secondary maritime schools in the area of safety culture on board ships and continuous safety improvement. For teacher support, a teacher's guide was also developed and evaluated in the study. 


\section{Material and methods}

\subsection{Development of a didactic design based on an interactive module}

The development of a suitable visualized didactic design for education emerged from the understanding of the learning problem and the users' needs. This, and other important aspects were met by applying Huang's (2005) recommended five-phased process for designing high-quality interactive multimedia learning modules: (1) understand the learning problem and the users' needs; (2) design the content to harness the enabling technologies; (3) build multimedia materials with web style standards and human factors principles; (4) user testing of the module; and (5) evaluate and improve design. The application of the five phases in the current study is described in the following sections.

\subsubsection{Phase 1-the learning problem}

The learning problem in the current study was to present the area of safety culture to correspond to the users' needs. Safety culture was presented by using an established structure of important areas and aspects. Based on keywords used in the safety research domain, the information was structured in six key areas important for safety and nine important aspects of safety culture according to research results (Ek and Akselsson 2005). The six key safety areas were: proactive learning, latent conditions, a system's view to safety, safety management system, leadership and participation, and man-technology system. The nine aspects of safety culture were: work situation, attitudes towards safety, risk perception, safety-related behaviours, communication, learning, reporting, justness, and flexibility. The challenge was to present this information in such a way that it would support the collective learning process among students and teachers. When presenting the information in the interactive module, efforts were made to adjust and apply a simpler and more understandable vocabulary that suited the young user group. For the students, this also became a starting point to the gradual build-up of a vocabulary in the safety and safety culture area.

Teachers should have appropriate education and training by exploring the interactive module with an accompanying teacher's guide in the form of a written manual.

\subsubsection{Phase 2-content design}

The second-phase dealt with the problem of finding a didactic approach with supporting technology to present the information to stimulate and strengthen the students' learning process. Since the research on safety culture to some extent is based on actual accidents and incidents, it was rather easy to find illustrating examples that could support the learners' associations to their own experiences and thereby support their learning. A suitable approach is Kolb's (1984) principles of experiential learning and Dixon's (1994) principles of collective learning. According to Kolb (1984), the learner's concrete experiences lead to reflective observations of them, which results in generalizations of abstract concepts and models, and finally testing these generalizations to generate new concrete experiences (Fig. 1a). 

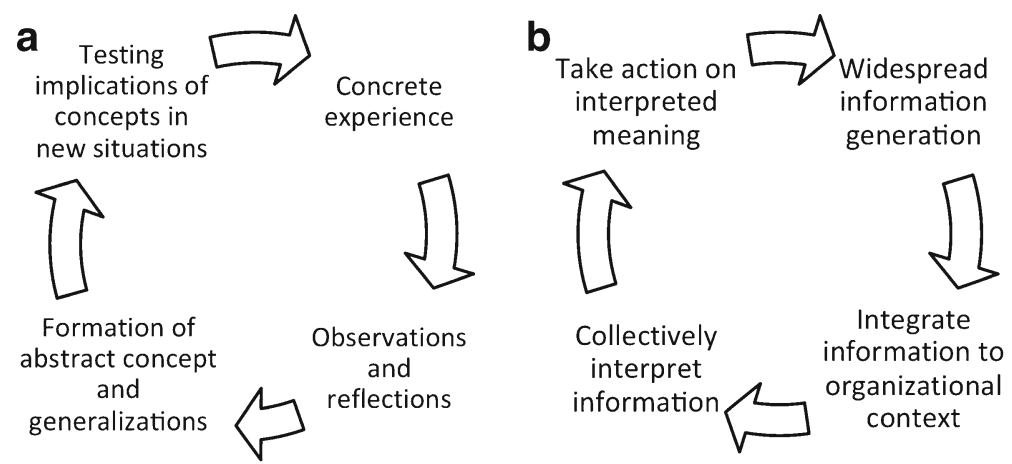

Fig. 1 a, b Kolb's model of experiential learning (Kolb 1984) and Dixon's model of organizational learning (Dixon 1994)

Dixon (1994) emphasizes the collective perspective of learning and describes the organizational learning process by applying and modifying Kolb's model to a collective context (Fig. 1b). Information that is generated in an organization has to be disseminated and interpreted by a number of individuals who then can act upon it. Dixon concludes that different perspectives among the members of the organization are essential to the company's learning process, otherwise learning does not occur. Thus, the understanding of the information and exchange of experiences are crucial; visualized material that supports understanding and interaction between learners should have great learning potential. This, in turn, relates to a communicative media form supported by seminar methods and an interactive media form supported by technology through the use of CDs and web resources according to Laurillard (2002).

In the current study, this approach led to the visualization of each of the six key areas of safety and nine aspects of safety culture by animations according to Höffler and Leutner's (2007) demands on specific combinations of instructionally relevant circumstances.

Three of the key areas (latent conditions, leadership and participation, mantechnology system) and eight safety culture aspects (work situation, attitudes towards safety, risk perception, safety-related behaviours, communication, reporting, justness, flexibility) were easily associated by applying scenarios. An example of this was how communication problems can lead to a collision between two ships. A selection of relevant scenarios was generated based on safety events that had occurred involving ships and safety culture issues. The final three key safety areas (proactive learning, a system's view to safety, safety management system) and one safety culture aspect (learning) were associated with regulations and processes. These were preferably animated with symbols showing relations and processes, such as the connection between different organizational levels of the maritime sector.

The leading criteria for selecting scenarios and describing processes was that the animations should provide widespread concrete experiences as well as abstract concepts to stimulate curiosity and interaction among students and teachers according to Kolb's (1984) and Dixon's (1994) learning principles.

Thus, animations were selected as the presentation technology of safety culture. Accordingly, the enabling technology needed to be some kind of multimedia software to organize and design a suitable user interface. The commercial software Adobe 
Flash was chosen since it makes it possible to create an interactive multimedia viewer suitable for publications on websites accessible with Flash Player free of charge, or on a CD without the need to install Flash Player. The reasoning and theoretical explanations of the didactic design and safety culture were included in the teacher's guide in preparation for the interactive lectures.

\subsubsection{Phase 3-build with standards and principles}

In this phase, the design ideas of the didactic design were realized as an interactive module that met the users' learning and needs: an interface with high usability. An appropriate definition of usability can be found in the ISO's Guidance on Usability, Ergonomic Requirements for Office Work with Visual Display Terminals, which states that it is '...the extent to which a product can be used by specified users to achieve specified goals with effectiveness, efficiency and satisfaction in a specified context of use' (ISO 9241-11 1998). This definition leads to important heuristics to consider. Heuristic refer to experience-based techniques for problem solving, learning, and discovery (Merriam-Webster 2012) and several different sets of heuristics exist for evaluating websites. Nielsen (2012) and Sharp et al. (2011) presents a list of ten important heuristics to evaluate interaction usability: (1) visibility of system status; (2) match between system and the real world; (3) user control and freedom; (4) consistency and standards; (5) error prevention; (6) recognition rather than recall; (7) flexibility and efficiency of use; (8) aesthetic and minimalist design; (9) help users recognize, diagnose and recover from errors; (10) help and documentation. In the current study, some of these heuristics were fulfilled by following established design standards from websites, such as symbols for navigation control and interaction with animations (Figs. 2 and 3). The 'error prevention' and 'help and documentation' heuristics were easily fulfilled since the interface was a viewer where the users explored information by navigating and viewing, and not by making changes or adding information.

Considering the heuristics 'aesthetic and minimalist design', Sharp et al. (2011) recommend a simple as possible design by removing unnecessary functionality, process steps and visual clutter. A design that is aesthetically pleasing and a pleasurable experience are also emphasized. Jordan (2000) also highlights the importance of pleasure of use that not only gives functional benefits but emotional ones. This position is clearly apparent among commercial multimedia products that strive for usage based on curiosity and attention.
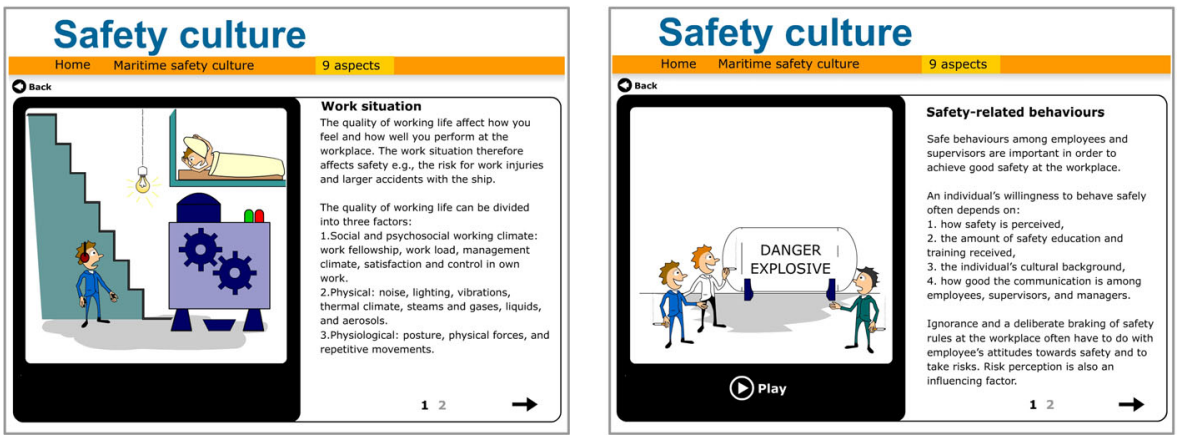

Fig. 2 Two screenshots of the aspects 'Work situation' and 'Risk assessment' 


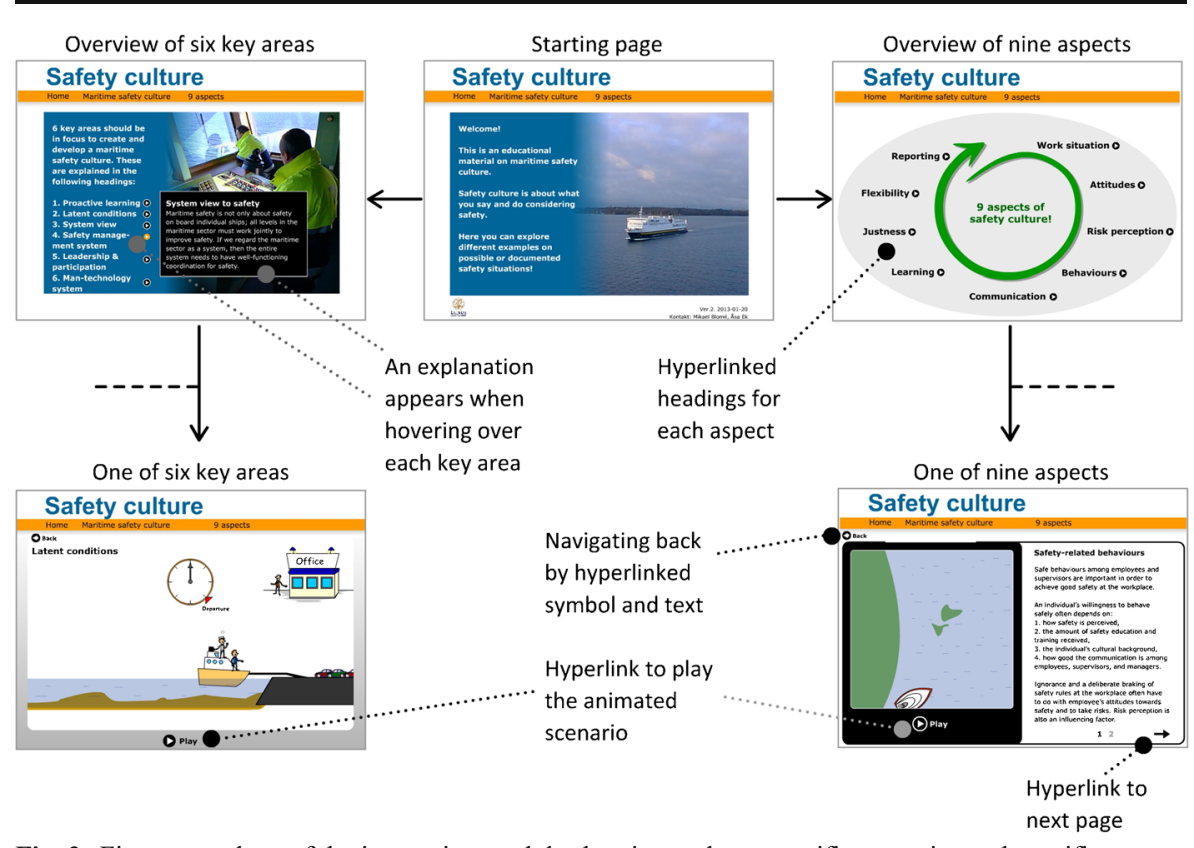

Fig. 3 Five screenshots of the interactive module showing paths to specific scenarios and specific aspects of safety culture

The scenarios in this study could have been viewed as photographs and films. But such media are easily out of fashion and are not minimalistic since they often contain unimportant, detailed information when the purpose is to show general principles; thus, they were excluded to avoid misinterpretation or leading the focus away from the relevant information. The scenarios were instead animated as 2D cartoon characters showing obvious expressions of either happiness or disappointment, and the environments were generated with a minimum level of details (Fig. 2).

Crucial information was animated to draw attention and provoke or inspire with shocking or humorous scenarios and dialogues, such as dangerously moving machinery, sparks flying from electric cables, and conflicting dialogues.

The explanations of the six key aspects were presented when the user hovered the cursor over the hyperlinked heading (Fig. 3), which displayed a large animation at the next level. The nine aspects of safety culture were displayed with a cyclic overview to stress the importance of continuous safety work, and animations with texts on the next level. The texts contained explanations and recommendations and were shortened to a maximum two pages with carefully chosen sentences and bullet lists. These guidelines resulted in minimizing the structure of the viewer to two levels, with a balanced information load between overview and detailed information. The teacher's guide provided more extensive explanations of the content of the didactic design with snapshots and explanatory texts.

\subsubsection{Phases 4 and 5-test and improvements}

These phases include user testing and evaluations of the didactic design and the interactive module to improve the design and evaluate the research study. During the earlier development phases of the didactic design, testing, evaluation, and improvements of the interactive 
module were made iteratively between the two authors (who had expert knowledge about interface design and safety culture, respectively). Then the interactive module was presented and discussed with two teachers at an upper-secondary maritime school in Sweden. The authors received feedback on the content and design of the interactive module and teacher's guide and made revisions, such as simplifying the vocabulary to fit the students. The teacher's guide also described a recommended usage of the interactive module to combine the interactive and communicative media with home assignments and discussion seminars based on theories of experiential learning. This approach was discussed with the teachers and it was decided to finally test and evaluate the didactic design and the interactive module with students.

\subsection{Tests and evaluations with students}

\subsubsection{The student group}

The educational material was tested and evaluated in a class of 16 upper-secondary maritime students during two visits. The students were 17-19 years old, both male and females, with computer experience. They were in the third and final year of their maritime education.

\subsubsection{Design and performance of testing procedure and evaluations}

The evaluation of the interactive module and how the didactic design worked involved usability, learning, and user experience aspects. Sharp et al. (2011) present a general framework to evaluate usability according to six usability goals: effectiveness, efficiency, safety, utility, learnability, and memorability. But they stress the importance of also considering them together with user experience goals (e.g. to be aesthetically pleasing). User experiences are defined by the standard ISO 9241-210 (2010) as, 'A person's perceptions and responses that result from the use or anticipated use of a product, system or service'. The safety aspect is left out since it involves protecting the user from dangerous conditions and undesirable situations such as systems to control machines or chemicals. Considering the evaluation in this study, the aspects of interest were:

- Usability:

Effectiveness - is the content relevant and meaningful?

Efficiency and utility of the didactic design-interactive and communicative media such as web material used in a classroom/seminar setting.

Learnability and memorability - understanding and remembering of how to explore the content of the interactive module.

- Learning the content: It is important to explore what the students learnt about safety culture.

- User experience: This was be explored to clarify the students' impressions and attitudes of the interactive module and the didactic design.

The evaluation process had a qualitative and triangulated approach including five steps: communicative seminar supported by the interactive module, home assignments, 
evaluation seminar a week later with a questionnaire, brainstorming session, and discussions.

The authors were introduced to a group of 16 students by a teacher on a scheduled seminar session and explored the content of the interactive module together with the students by providing explanations and exchanging experiences. The teacher was also present but kept a low profile and only provided necessary clarifications to students' associations from earlier phases of their education, such as practice on board ships.

At the end of the session, a home assignment was handed out. The students were to answer two questions: 1. What is safety culture? 2. Describe a situation you have experienced (e.g. during your practice) showing an example of good or bad safety culture. The purpose of the assignment was to evaluate the learning and efficiency aspects.

The authors revisited the students at a seminar a week later for evaluation. It started with collecting the home assignments, and handing out a questionnaire containing questions about the usability and user experience of the interactive module and its content. The questionnaire was filled in by the students and collected (see Table 1 for items included). The authors then interviewed the student group about the contents of the interactive module during a brainstorming session, were any student could think aloud to remember the contents while the authors wrote down and displayed the answers on a big screen. The authors then presented the interactive module to the students, and compared it to the answers given. The evaluation closed with a general discussion with the students and the teacher about the didactic design based on the questions in the questionnaire. The discussions during both the presentation and evaluation visits were recorded for documentation.

The collected data went through a content analysis (Patton 2002), which reduced the qualitative data to identify core consistencies and meanings. The content analysis started off with an inductive approach to discover patterns, themes, and categories. Then deductive comparisons were made with definitions of usability from to the ISO 9241-210 (2010) and Sharp et al. (2011), and user experience Sharp et al. (2011).

\section{Results}

\subsection{The interactive module}

The information and knowledge of safety culture were visualized with scenarios of life on board, illustrations and animations (Fig. 3). The starting page introduced and generally defined safety culture and provided two paths into the educational material either via the six key safety areas, or via the nine aspects of safety culture. The interactive module provided examples to illustrate concrete experiences to support explanations and recognition for students and teachers, and abstract concepts and models to explain generalizations. The teacher could easily choose to view suitable information about safety culture with the interactive module depending on the on-going discussions with the students. The teacher's guide contained screenshots with written explanations of the interactive module's structure, and the didactic design of recommended usage according to the principles of experiential and interactive learning. 
Table 1 Summarized results from the questionnaire of usability and user experience, $n=16$ students

\begin{tabular}{|c|c|c|c|c|}
\hline & $\begin{array}{l}\text { General } \\
\text { answers }\end{array}$ & $\begin{array}{l}\text { Distribution, } \\
\%\end{array}$ & Explanations & $\begin{array}{l}\text { Distribution, } \\
\%\end{array}$ \\
\hline \multicolumn{5}{|l|}{ Usability aspects } \\
\hline \multirow[t]{3}{*}{$\begin{array}{l}\text { Relevance: Is the } \\
\text { subject meaningful? }\end{array}$} & Yes (15) & 94 & $\begin{array}{l}\text { Personal health and safety } \\
\text { in future work (8) }\end{array}$ & 50 \\
\hline & \multirow[t]{2}{*}{ Yes and no (1) } & 6 & $\begin{array}{l}\text { Responsibility to others } \\
\text { in future work (5) }\end{array}$ & 31 \\
\hline & & & Learn better (4) & 25 \\
\hline \multirow{2}{*}{$\begin{array}{l}\text { Learnability and } \\
\text { memorability } \\
\text { (understand the content } \\
\text { of the module) }\end{array}$} & \multirow[t]{2}{*}{ Yes (16) } & 100 & $\begin{array}{l}\text { Animations and } \\
\text { pictures (10) }\end{array}$ & 63 \\
\hline & & & Seminar form (4) & 25 \\
\hline \multirow{5}{*}{$\begin{array}{l}\text { Efficiency and utility } \\
\text { of the pedagogical } \\
\text { concept: How did the } \\
\text { concept work out? }\end{array}$} & Good (14) & 88 & $\begin{array}{l}\text { Supports thinking } \\
\text { and discussion (7) }\end{array}$ & 44 \\
\hline & \multirow{4}{*}{$\begin{array}{l}\text { No general } \\
\text { answer } \\
\text { given (2) }\end{array}$} & 13 & Structure and focus (4) & 25 \\
\hline & & & Needs to be developed (2) & 13 \\
\hline & & & Fun (2) & 13 \\
\hline & & & A little boring at times (1) & 6 \\
\hline \multicolumn{5}{|l|}{ User experience aspects } \\
\hline \multirow{5}{*}{$\begin{array}{l}\text { The module and the } \\
\text { pedagogical concept: } \\
\text { What do you think } \\
\text { of this? }\end{array}$} & Good (12) & 75 & $\begin{array}{l}\text { Fun and helpful with } \\
\text { animations (3) }\end{array}$ & 19 \\
\hline & \multirow{4}{*}{$\begin{array}{l}\text { No general } \\
\text { answer } \\
\text { given (4) }\end{array}$} & 25 & Fun, not boring (2) & 13 \\
\hline & & & $\begin{array}{l}\text { Good with new approach } \\
\text { and external organizers (2) }\end{array}$ & 13 \\
\hline & & & $\begin{array}{l}\text { Should have more } \\
\text { information in text (1) }\end{array}$ & 6 \\
\hline & & & $\begin{array}{l}\text { Preferred real films } \\
\text { to animations (1) }\end{array}$ & 6 \\
\hline \multirow[t]{3}{*}{ Adjustments/suggestions? } & Yes $(10)$ & 63 & $\begin{array}{l}\text { Add sound effects to } \\
\text { the animations (4) }\end{array}$ & 25 \\
\hline & \multirow[t]{2}{*}{ No (6) } & 38 & Add more music (2) & 13 \\
\hline & & & Add real films (2) & 13 \\
\hline
\end{tabular}

\subsection{Testing procedure and evaluations}

The presentation of the interactive module was successful in immediately creating a discussion about safety culture and the students could easily connect the scenarios presented to the knowledge and safety experiences they had gained during their earlier practice on board vessels. The usability and user experience aspects represented in the questionnaire are summarized in Table 1; the learning outcome results from the home assignment, questionnaire, and brainstorming session are summarized in Table 2; and the results of the final discussion with the students are summarized in Table 3. The majority of the students found safety culture subject to be relevant and highlighted for example 
Table 2 Summarized results of learning outcome from home assignment, questionnaire, and brainstorming session, $n=16$ students

\begin{tabular}{|c|c|c|}
\hline Methods and questions & Answers & $\begin{array}{l}\text { Distribution, } \\
\%\end{array}$ \\
\hline \multirow[t]{4}{*}{ Home assignment: What is safety culture? } & 1. Safety management and practice (10) & 63 \\
\hline & 2. Attitude to safety is important (7) & 44 \\
\hline & 3. Regulations and recommendations (6) & 38 \\
\hline & 4. Safety equipment (5) & 31 \\
\hline \multirow{8}{*}{$\begin{array}{l}\text { Home assignment: Describe a situation you } \\
\text { have experienced (e.g. during your } \\
\text { practice) that shows an example of good } \\
\text { or bad safety culture. }\end{array}$} & 1. Ignore using safety equipment (6) & 38 \\
\hline & 2. Accident or near accident (3) & 19 \\
\hline & 3. Using safety equipment (2) & 13 \\
\hline & 4. Good equipment (2) & 13 \\
\hline & 5. Poor or incorrect safety equipment (2) & 13 \\
\hline & 6. Good safety organization (2) & 13 \\
\hline & $\begin{array}{l}\text { 7. Good education about action plans and } \\
\text { equipment (1) }\end{array}$ & 6 \\
\hline & $\begin{array}{l}\text { 8. Poor education about action plans and } \\
\text { equipment (1) }\end{array}$ & 6 \\
\hline \multirow{2}{*}{$\begin{array}{l}\text { Questionnaire: Did you learn something } \\
\text { new? }\end{array}$} & 1. Yes (10) & 63 \\
\hline & 2. No (6) & 38 \\
\hline \multirow[t]{2}{*}{ Questionnaire: What do you remember? } & 1. Overview and general principles (8) & 50 \\
\hline & 2. Details of the subject (4) & 25 \\
\hline $\begin{array}{l}\text { Brainstorm: What do you remember of the } \\
\text { module? }\end{array}$ & $\begin{array}{l}\text { The group of } 16 \text { students could recall and } \\
\text { describe all animations of the } 6 \text { key safety } \\
\text { areas and } 9 \text { safety culture aspects of the } \\
\text { module. }\end{array}$ & \\
\hline
\end{tabular}

personal health and safety as well as responsibility to others in future work. All students could understand the content of the module and $63 \%$ explained that this was because of the animations and pictures. The user experience of the didactic design was in general good.

\subsubsection{Participating teacher's evaluation}

The participating teacher (52 years old with computer experience) was at first sceptic to the illustrations because they seemed too simple and he did not understand how they should be used. But during the two seminars he could see that the students were very positive to the simple animations that visualized different safety culture scenarios. On the whole, the student group could remember and describe all scenarios a week after the presentation of the material. The teacher considered it important for the students to have insights about different safety culture issues and reasons for different behaviours in order for them to better control or influence situations and circumstances in future work situations on board ships. He also felt that he would be able to execute the didactic design with support from the teacher's guide. 
Table 3 Summarized results of the final discussion with open questions and brainstorming answers by the students, $n=16$ students

\begin{tabular}{|c|c|}
\hline Questions & Answers \\
\hline Spontaneous comments? & $\begin{array}{l}\text { Better than the usual books and worksheets. } \\
\text { Good to think on our own and reasoning. } \\
\text { The animations worked out well. }\end{array}$ \\
\hline How did it work out compared to realistic films? & $\begin{array}{l}\text { Better or comparable, it becomes more clear and } \\
\text { obvious. It's good having explanatory texts } \\
\text { on the side. }\end{array}$ \\
\hline How should it be used? & $\begin{array}{l}\text { Someone to lead the group discussions. } \\
\text { It might be difficult on your own; you need } \\
\text { someone to discuss it with. } \\
\text { Must use it in a group, otherwise its boring. }\end{array}$ \\
\hline Improvements? & $\begin{array}{l}\text { There should have been sound, speech and effects. } \\
\text { Sometimes background music. } \\
\text { A recoded interview with someone would make } \\
\text { it more convincing. } \\
\text { More explanations about the checklists and what } \\
\text { they are good for. }\end{array}$ \\
\hline
\end{tabular}

\section{Discussion}

\subsection{The didactic design}

This paper reports on the development and evaluation of an interactive didactic design. The didactic design is relevant to organizations that want to enhance their awareness, communication, and learning of maritime safety by means of interactive visualization. Huang's (2005) recommended five-phased design process worked well to structure the transformation process of scientific knowledge and principals of safety culture into an interactive learning module.

The efforts for an aesthetic and minimalistic design resulted in scenarios with animated cartoon characters showing obvious expressions of either happiness or disappointment, and the on-board environments were generated with minimal details. The interactive module received good scores in the questionnaire on usability and user experience but some students wanted more realism through the use of films. The topic was further discussed with the student group (Table 3). However, the general opinion among the students was that they considered animations to be better or comparable, also having the advantage of giving clear and obvious examples. Most students appreciated the interactive module as good, fun and helpful, which is positive from the user experience perspective (Sharp et al. 2011). However, it should not be gimmicky or give a non-serious impression. No one made such comments, but a few students suggested that an accompanying recorded interview would make it more convincing. There were also some who wanted more explanations in text along with the animations. The amount of text may be sufficient for using the interactive module in the seminar form, but for individual exploration, there may be a need to expand the information, which is a subject for further research. The results indicated 
good memorability and understanding of how to explore the interactive module and there were no questions or comments.

Adding sound effects was the most outstanding suggestion to improve the interactive module. Speech, background music, and other sound effects were recommended. These sounds are common in computer games and smartphone applications used by the target group of young students. Sound additions should be made carefully since too much sound could be disturbing and one should also consider a more diversified age group of students.

\subsection{Learning outcome after using the didactic design}

All students felt that the subject of safety culture was meaningful and highlighted the importance of it for personal safety and health and for others by responsible behaviour. This was not an entirely new insight for the students: $38 \%$ answered they did not learn anything new, but $100 \%$ thought that the animations and pictures of the interactive module along with the seminar form made the subject easy to understand. The results of the learning outcome were positive with no misunderstandings and the students' answers to what safety culture covered major and high-order aspects of a safety culture (Table 2). This corresponded well to the content of the interactive module. The group of students could recall and describe all animations, but the individual answers were either more general or included examples of details from the interactive module. Perhaps more time and a different formulation of questions about the content would have resulted in more complete answers. However, deeper learning according to the experiential learning process (Kolb 1984) was supported by the students' adequate examples of personal experiences, mostly related to safety equipment but also to safety organization and education (Table 2).

\subsection{Further development and research}

The students appreciated the didactic design since it supported thinking and discussion with a structure, which supports Dixon's (1994) model of organizational learning. It was necessary to have someone to lead the discussions, and some stated that they liked having someone outside the course, which also strengthened the user experience by adding surprise and excitement. The students stressed the importance of being able to discuss the content with someone, since it added a positive overall dimension. One can conclude that the positive response to the interactive module in this study is only evident in combination with the seminar to support the learning process. It would be interesting to develop and evaluate the interactive module as a stand-alone module such as an application for smart phones and tablets for individual usage and explore further didactic and pedagogical approaches. Students could then gain control of their learning experience by freely pursuing information based on individual learning strategies and curiosity, and the interaction during classroom teaching could be supported with interactive home assignments and reflections.

This study integrated the participative development of a didactic design including a teacher's guide with Huang's (2005) five-phased design process. This proved to ensure efficient usage of the interactive module in a seminar form and a smooth hand over to the participating teacher, who became convinced of the benefits of the module 
during the seminars and felt confident in using the material on his own supported by the teacher's guide.

\section{Conclusions}

The study resulted in a didactic design including an interactive module with suitable visualizations and a teaching guide to support teachers in presenting the area of safety culture on board vessels and continuous safety improvement. The results were overall positive regarding usability, user experience, and learning outcome with a potential for further development and implementations. The most important findings were:

- Huang's (2005) five-phased design process was suitable to structure the transformation process of scientific knowledge and principals of safety culture into an interactive learning module.

- The design of the interactive module with scenarios of animated cartoon characters in environments with minimal details to give clear and obvious examples supports Sharp et al. (2011) recommendation of an aesthetic and minimalistic design.

- All students felt that the subject of safety culture was meaningful and highlighted the importance of safety culture for personal safety and health and for others by responsible behaviour.

- Most students appreciated the interactive module as good, fun, and helpful.

- The animations of the interactive module along with the seminar form made the subject easy to understand, and connected to individual experiences, thinking, and discussion which support experiential and organizational learning.

- The interactive module could be improved by carefully adding speech, background music, and other sound effects.

- The didactic design should be described in a teacher's guide and should be considered in each step of the design process of the interactive module.

- Teachers should participate during the development process to ensure teachers' and students' perspectives on the didactic design.

There are several possibilities for further development of the interactive module and the didactic design. It would be interesting to evaluate the interactive module as a stand-alone module for individual usage and to explore alternative pedagogic approaches. There is also a potential to adapt and develop the didactic design for other users in the maritime sector, for example, vessel crews.

Acknowledgments This project was supported by grants from the Swedish Mercantile Marine Foundation.

Open Access This article is distributed under the terms of the Creative Commons Attribution License which permits any use, distribution, and reproduction in any medium, provided the original author(s) and the source are credited.

\section{References}

Blomé M, Johansson CR, Odenrick P (2003) Computer supported visualisation of quality systems developed by network teams. Appl Ergon 34(3):239-247 
Blomé M, Johansson CR, Odenrick P (2006) Visualization of ergonomic guidelines - a comparison of two computer aided systems to support vehicle design. Int J Ind Ergon 36(6):571-580. doi:10.1016/ j.ergon.2005.08.006

Brooks R, Fuller A, Johanna LW (2012) Changing spaces of education: new perspectives on the nature of learning. Routledge, New York

Bruneel J, D'Este P, Salter A (2010) Investigating the factors that diminish the barriers to universityindustry collaboration. Res Policy 39(7):858-868. doi:10.1016/j.respol.2010.03.006

Carney R, Levin J (2002) Pictorial illustrations still improve students' learning from text. Educ Psychol Rev 14(1):5-26. doi:10.1023/a:1013176309260

Chung AZQ, Shorrock ST (2011) The research-practice relationship in ergonomics and human factors - surveying and bridging the gap. Ergon Hybrid Autom Syst 54(5):413-429

Dixon N (1994) The organizational learning cycle: how we can learn collectively. McGraw-Hill, London

Dowie J (1996) The research-practice gap and the role of decision analysis in closing it. Health Care Anal 4(1):5-18

Ek Å, Akselsson R (2005) Safety culture on board six Swedish passenger ships. Marit Policy Manag 32(2):159-176

Fletcher S (2001) Empowering learning through design: a comparative analysis of ICM course development for web-based and classroom delivery. Mar Policy 25(6):457-466. doi:10.1016/s0308-597x(01)00030-6

Fletcher S, Dodds W (2003) The use of a virtual learning environment to enhance ICM capacity building. Mar Policy 27(3):241-247. doi:10.1016/s0308-597x(03)00003-4

Gagnon ML (2011) Moving knowledge to action through dissemination and exchange. J Clin Epidemiol 64(1):25-31. doi:10.1016/j.jclinepi.2009.08.013

Graham ID, Logan J, Harrison MB, Straus SE, Tetroe J, Caswell W, Robinson N (2006) Lost in knowledge translation: time for a map? J Contin Educ Health Prof 26(1):13-24. doi:10.1002/chp.47

Huang C (2005) Designing high-quality interactive multimedia learning modules. Comput Med Imaging Graph 29:223-233

Höffler TN, Leutner D (2007) Instructional animation versus static pictures: a meta-analysis. Learn Instr 17(6):722-738. doi:10.1016/j.learninstruc.2007.09.013

ISO 9241-210 (2010) Ergonomics of human-system interaction-part 210: human-centered design process for interactive systems. European Committee for Standardization

ISO 9241-11 (1998) Ergonomic requirements for office work with visual display terminals (VDTs) — part 11: guidance on usability

Jordan PW (2000) Designing pleasurable products: an introduction to the new human factors. Taylor and Francis, London

Kolb DA (1984) Experiential learning: experience as the source of learning and development. PrenticeHall, Englewood Cliffs

Laurillard D (2002) Rethinking university teaching: a conversational framework for the effective use of learning technologies, 2nd edn. RoutledgeFalmer, London

Lewalter D (2003) Cognitive strategies for learning from static and dynamic visuals. Learn Instr 13(2):177189. doi:10.1016/s0959-4752(02)00019-1

Levie W, Lentz R (1982) Effects of text illustrations: a review of research. Educ Technol Res Dev 30(4):195-232. doi:10.1007/bf02765184

Lomas J (1993) Diffusion, dissemination, and implementation: who should do what? Ann N Y Acad Sci 703:226-235

Mayer RE (1989) Systematic thinking fostered by illustrations in scientific text. J Educ Psychol 81(2):240-246

Mejia MQ, Mukherjee PK, Akselsson R (2007) The ISM Code in the context of Swedish port state control statistics. Ocean Yearb Online 21:405-426

Merriam-Webster (2012) Heuristic. http://www.merriam-webster.com/dictionary/heuristic. Accessed September 20, 2012

Moffatt S, Phillimore P, Hudson E, Downey D (2000) “Impact? What impact?" Epidemiological research findings in the public domain: a case study from north-east England. Soc Sci amp; Med 51(12):17551769. doi:10.1016/s0277-9536(00)00108-8

Muirhead PMP (2004) New technology and maritime training in the 21st century: implications and solutions for MET institutions. WMU J Marit Aff 3(2):139-158

Nielsen J (2012) Ten usability heuristics. http://www.useit.com/papers/heuristic/heuristic_list.html. Accessed August 2012

Patton MQ (2002) Qualitative research and evaluation methods, 3rd edn. Sage, London

Sharp H, Rogers Y, Preece J (2011) Interaction design: beyond human-computer interaction, 3rd edn. Wiley, Chichester

Tversky B, Morrison JB, Betrancourt M (2002) Animation: can it facilitate? Int J Human-Comput Stud 57(4):247-262. doi:10.1006/ijhc.2002.1017 